\title{
A prospective cohort study of a clip-on fixed functional appliance
}

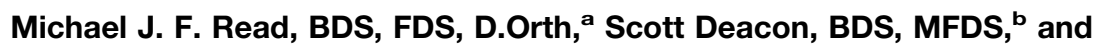 \\ Kevin O'Brien, FDS, D.Orth, MSc, PhD' \\ Manchester, United Kingdom
}

The aim of this study was to evaluate the effectiveness of a fixed Twin-block appliance by using a study with a prospective cohort design. Thirty-two children were included in the study over a 2-year period. Cephalometric data were analyzed with the Pancherz cephalometric analysis. Study models were analyzed with the PAR index, and the treatment processes were recorded from the patients' records. The results showed that this appliance was effective in correcting Class II malocclusion; the noncompliance rate was only $6 \%$. It can be concluded that this method of treatment might have some advantages over other fixed and removable functional appliances, but this should be tested with randomized trial methodology. (Am $\mathrm{J}$ Orthod Dentofacial Orthop 2004;125:444-9)

A major problem with most forms of functional appliance therapy for treating Class II malocclusions is that much patient cooperation is required. Over the last few years, several appliance types have been developed that are fixed to the patient's teeth to increase compliance. ${ }^{1,2}$ However, although the morphological effects of these appliances have been investigated, only 1 study has evaluated their cooperation rates: a multicenter randomized controlled trial that compared the effectiveness of the Herbst and the Twin-block appliances. ${ }^{3}$ The authors concluded that both appliances had similar effects on the dentition and skeletal pattern, but the noncompletion rates were $12 \%$ with the Herbst and 33\% with the Twin-block. Unfortunately, these authors also found that the trade-off for the greater completion rate with the Herbst was more visits to repair fractured appliance components or debonds.

After that study, we decided that a problem with the Herbst appliance was that the link between the mandibular and maxillary dentitions was fixed. This might lead to high levels of stress in the components, resulting in fracture or debonds. We thought that a method of reducing this was to develop a fixed functional appli-

From the Unit of Orthodontics, Department of Dental Medicine and Surgery, University of Manchester, Manchester, United Kingdom.

${ }^{\mathrm{a} C}$ Consultant orthodontist.

${ }^{\mathrm{b}}$ Graduate student.

${ }^{\mathrm{c}}$ Professor and chair.

Reprint requests to: Mike Read, Unit of Orthodontics, Department of Medicine and Surgery, Higher Cambridge St, Manchester M15 6FH, United Kingdom; e-mail, Mike.Read@man.ac.uk.

Submitted, January 2003; revised and accepted, May 2003. $0889-5406 / \$ 30.00$

Copyright $(\odot) 2004$ by the American Association of Orthodontists. doi:10.1016/j.ajodo.2003.05.011 ance in 2 separate parts. As a result, we decided to adapt the Twin-block appliance so that it could be fixed to the teeth.

The Twin-block appliance was developed in Scotland by W. Clark. It consists of maxillary and mandibular removable appliances retained with Adams clasps on the first permanent molars and first premolars; the active components are acrylic inclined blocks that posture the mandible forward when the patient is in occlusion. Details of this appliance are fully reported elsewhere. ${ }^{4}$ This is the most popular functional appliance in the United Kingdom. ${ }^{5}$

The aims of this study were to evaluate the effectiveness of a modified version of this appliance in a prospective cohort.

\section{MATERIAL AND METHODS}

This modified appliance was first described by Read in a case report. ${ }^{6}$ The acrylic blocks are attached to bands placed on the maxillary first molars and the mandibular premolars. The method of attachment varied with the first few appliances that were made, but, essentially, the blocks are attached by Wilson attachments on the lingual/palatal surface of the bands. On the buccal side, a retaining wire $(0.7 \mathrm{~mm}$, stainless steel) is fitted into the maxillary molar band headgear tube, and a similar wire is fitted into a tube soldered onto the wings of the edgewise bracket on the mandibular band (Fig 1). The appliance cannot be removed by the patient, and the small gap between the blocks and the occlusal surface is filled with glass ionomer cement. The blocks are standard Twin-block design with steeply inclined planes interlocked at about $70^{\circ}$ to the occlusal plane. The jaw registration was taken with approxi- 

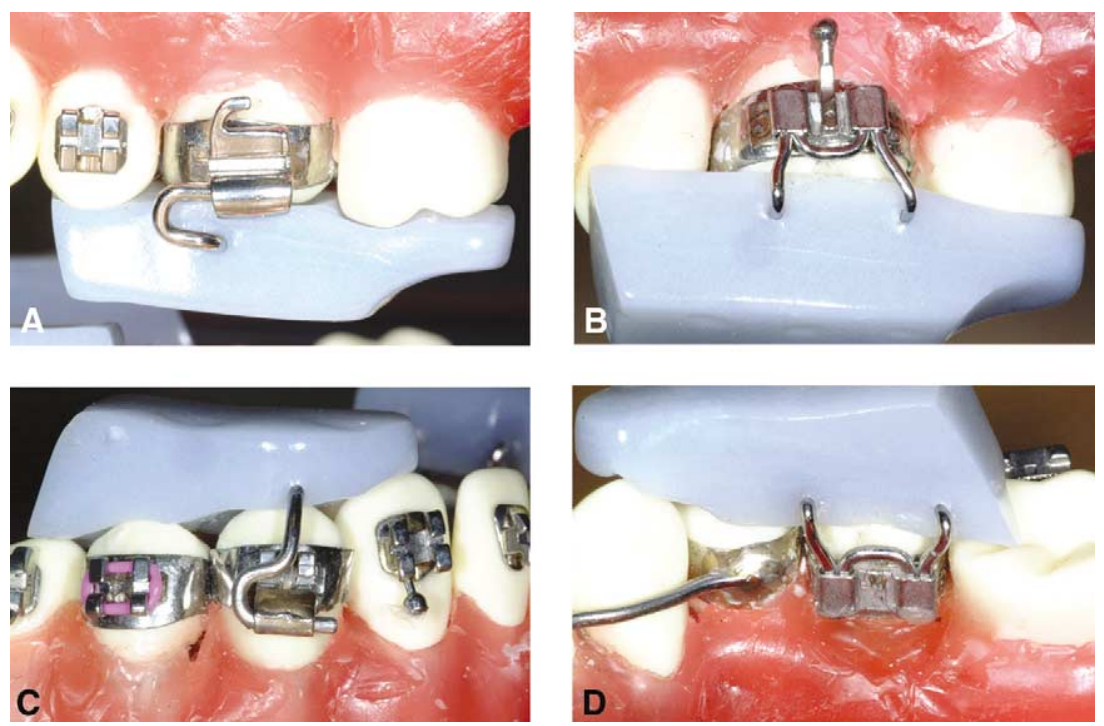

Fig 1. A, Buccal view of maxillary fixed Twin-block component; B, palatal view of maxillary fixed Twin-block component; C, buccal view of mandibular fixed Twin-block appliance; $\mathbf{D}$, lingual view of mandibular fixed Twin-block appliance.

mately 7-8 $\mathrm{mm}$ protrusion or advanced so that the incisors were edge to edge, and the blocks are $7 \mathrm{~mm}$ apart in the buccal segments. Reactivation of the blocks was carried out when necessary by adding acrylic to the inclined surface of the maxillary block.

After the appliance was fitted, the patients attended the clinic every 4 weeks. At the second or third visit, edgewise straight-wire fixed appliances were placed on the maxillary and mandibular teeth. The amount of overjet reduction was checked every 2 months, and, when the incisors were an in edge-to-edge relationship, the blocks were removed, and the treatment was completed with full edgewise fixed appliances.

An example of a patient treated with this appliance is shown in Figures 2 to 5. To evaluate the effectiveness of this appliance, we decided to carry out a prospective cohort study. Every patient who started treatment between May 1998 and November 2000 was included.

The inclusion criteria for treatment were (1) Class II Division 1 incisal relationship, (2) overjet greater than $7 \mathrm{~mm}$, (3) second premolars fully erupted, and (4) less than 15 years of age.

All patients were either treated or supervised by 2 operators (M.R. and K.O.)

We collected the following data:

- Study casts, analyzed with the peer assessment rating (PAR index), weighted with the UK weights. ${ }^{7}$ The examiner had been calibrated in the PAR index by a trained examiner.
- Cephalometric radiographs, analyzed with the Pancherz analysis. ${ }^{1}$ We also recorded the stages of maturation of the cervical spine from the pretreatment cephalograms using the method described by Hassel and Farman. ${ }^{8}$ Thirty sets of radiographs were reanalyzed, and errors for the cervical spine staging and Pancherz analysis were evaluated with the kappa statistic, intraclass correlation coefficient, and Student $t$ tests.

- Treatment process, obtained from the patients' records.

- Any iatrogenic damage to the dentition or the gingival tissues.

The data from all the patients were analyzed regardless of the outcome of the treatment.

Descriptive data were generated for all variables. Further data analysis was done with a regression analysis on the dependent variable of the final skeletal discrepancy (A/OLp minus Pg/OLp) with independent variables of sex, cervical spine stage, initial skeletal discrepancy, and initial overjet.

\section{RESULTS}

Thirty-two patients were included in the study. Data on the process of treatment are shown in Table I. The mean pretreatment PAR score was 35.06 (SD 7.4); the mean posttreatment score was 6.25 (SD 4.9), with a mean reduction of 29.21 (SD 9.02) points. Descriptive data for cephalometric variables are shown in Table II. 

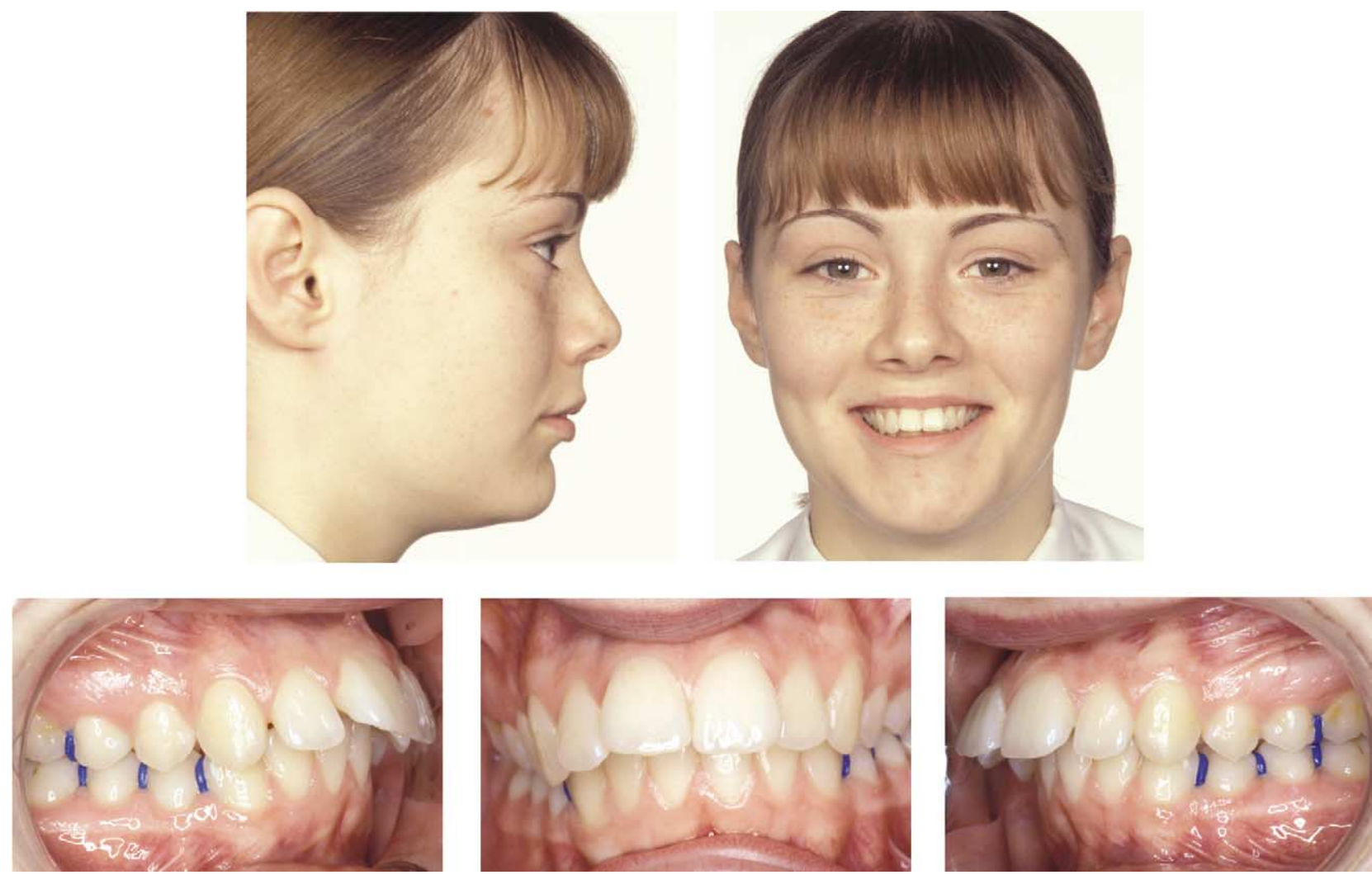

Fig 2. Pretreatment photographs.
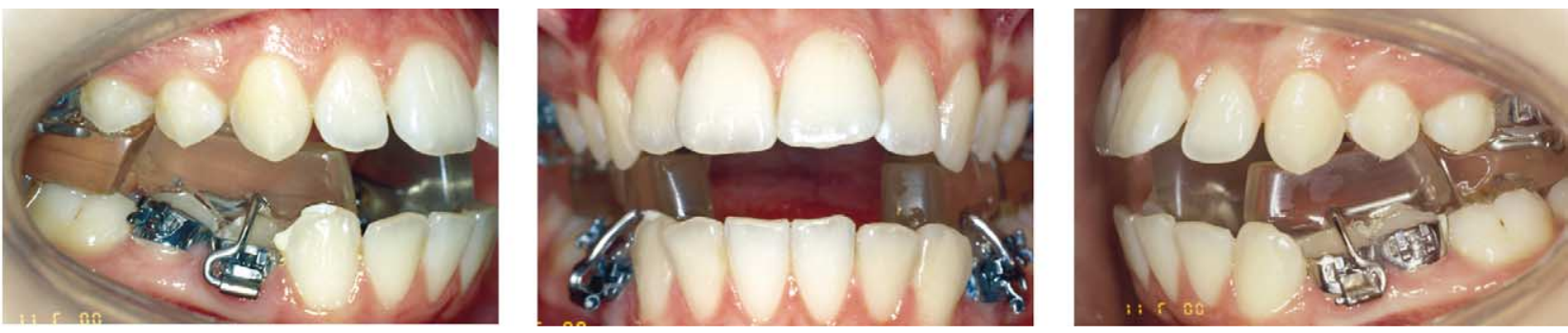

Fig 3. Clip-on fixed functional appliance in place.
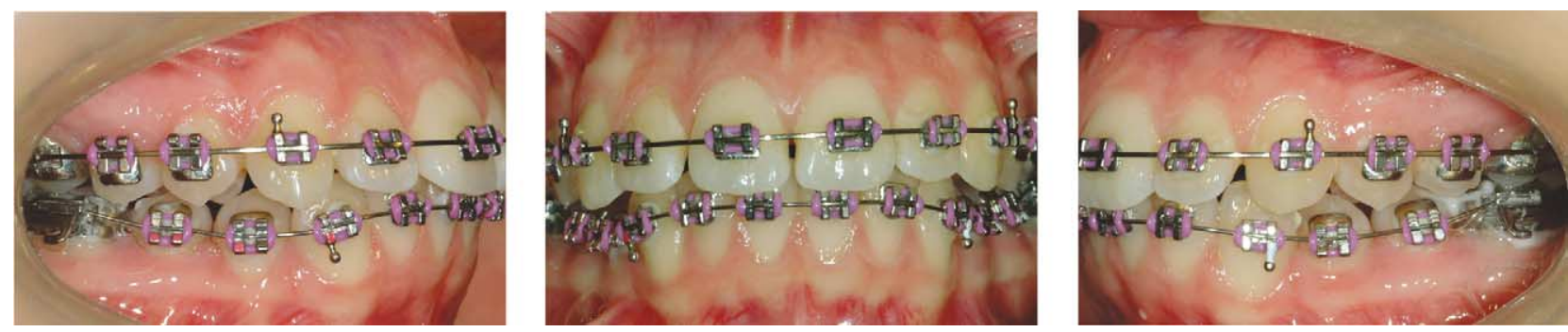

Fig 4. Fixed appliance phase of treatment. 

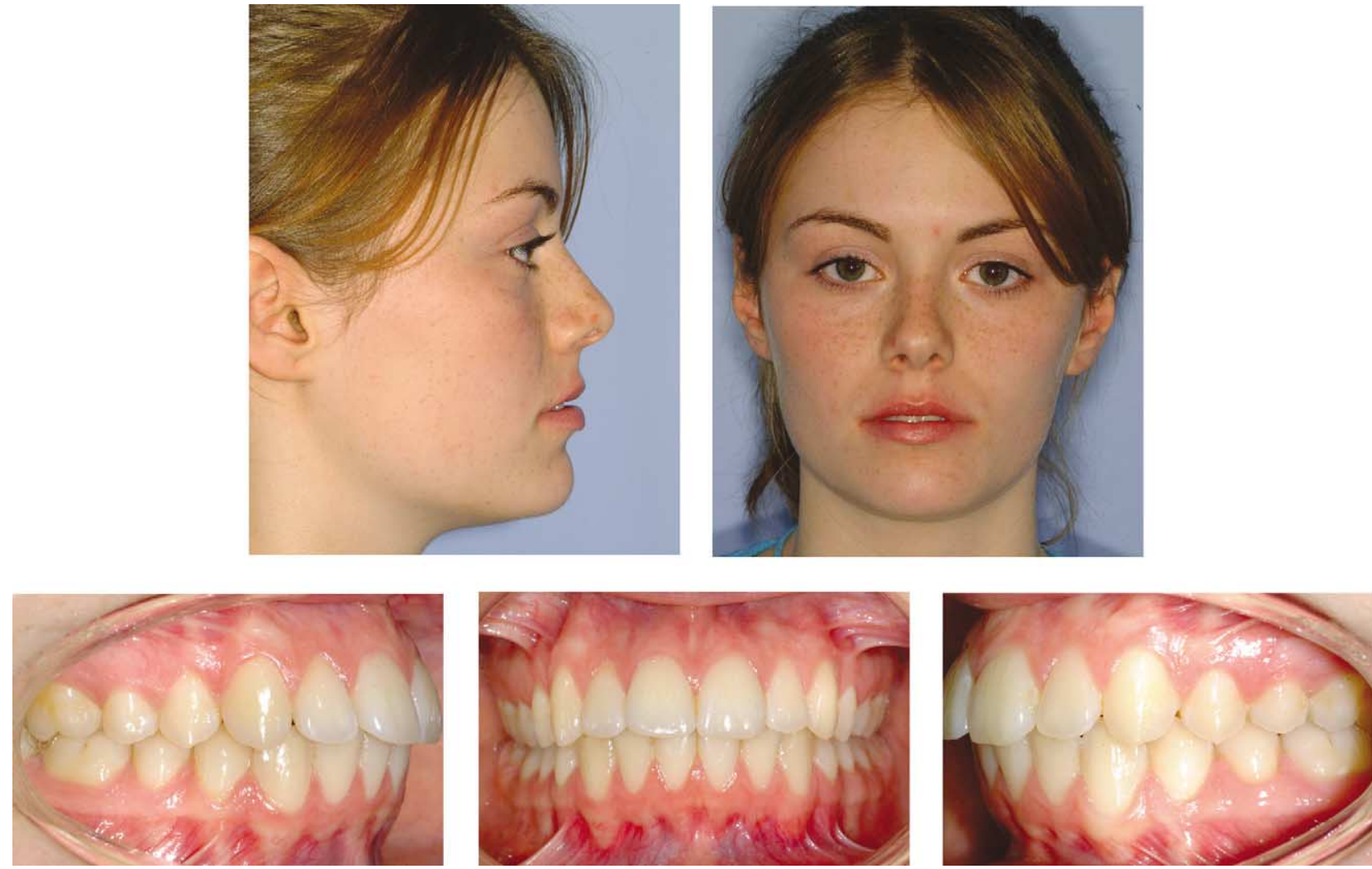

Fig 5. Posttreatment photographs.

Table I. Process of treatment

\begin{tabular}{lcrrr}
\hline & Minimum & Maximum & Mean & SD \\
\hline Total treatment time (months) & 9.00 & 30.00 & 20.1852 & 5.9423 \\
Time in functional appliance & 2.00 & 12.00 & 5.1333 & 1.9954 \\
Total number of visits & 13.00 & 33.00 & 1.6000 & 5.7930 \\
Number of visits in functional phase & 4.00 & 13.00 & 7.8333 & 2.1509 \\
Additional visits to replace loose blocks & .00 & 3.00 & 2.3000 & 1.5120 \\
Additional visits to repair fractured blocks & .00 & 3.00 & .5333 & .8604 \\
\hline
\end{tabular}

Table III contains data on the changes in cephalometric variables, including normal growth. Figures 6 and 7 illustrate the amounts of skeletal and dental change as a proportion of overjet and molar correction.

The regression analysis on skeletal discrepancy showed that the only variable that had an effect in the model was the initial skeletal discrepancy with a beta value of $0.718(95 \% \mathrm{CI}=0.41$ to 1.02$)\left(\mathrm{R}^{2}=0.535\right.$, model significance $=0.000$ ).

Two patients failed to complete the functional appliance phase of treatment. One could not wear the appliance immediately after fitting and insisted that it be removed, and another patient had removable Twinblocks fitted after repeated fracturing of the mandibular appliance. Also, 3 patients had their treatment finished early after requesting to terminate their fixed appliances during the second phase of treatment.

No patient had decalcification or long-term gingival disease secondary to the appliance.

\section{Cephalometric error}

The results of the error analysis for the cervical spine data showed a kappa value of 0.94. The error analysis for the Pancherz analysis showed that the intraclass correlation coefficient for cephalometric landmark identification and digitizing ranged from 0.84 for ii/OLp to 0.98 for A/OLp. The root mean square (standard deviation of the error) ranged from $0.45 \mathrm{~mm}$ 
Table II. Pancherz analysis cephalometric data at start and end of treatment

\begin{tabular}{|c|c|c|c|c|}
\hline & \multicolumn{2}{|c|}{ Before } & \multicolumn{2}{|c|}{ After } \\
\hline & Mean & $95 \% C I$ & Mean & $95 \% C I$ \\
\hline Overjet: Is/OLp minus ii/OLp & +9.66 & +8.97 to +10.35 & +3.01 & +2.03 to +3.99 \\
\hline Molar relation: Ms/OLp minus mi/Ollp & +2.11 & +1.38 to +2.83 & -1.94 & -2.63 to -1.25 \\
\hline Maxillary base: A point to Olp & +72.35 & +70.62 to +74.07 & +72.61 & +70.76 to 74.45 \\
\hline Mandibular base: $\mathrm{Pg} / \mathrm{Olp}$ & +71.89 & +69.67 to +74.10 & +75.84 & +73.46 to +78.22 \\
\hline Condylar head: $\mathrm{Co} / \mathrm{Olp}$ & -13.30 & -14.67 to -11.94 & -14.06 & -15.25 to -12.86 \\
\hline Mandibular length: pg/Olp plus co/OLP & +58.58 & +55.76 to +61.40 & +61.78 & +58.79 to +64.78 \\
\hline Maxillary incisor: is/Olp & +80.69 & +78.93 to +82.45 & +79.46 & +77.22 to +81.70 \\
\hline Mandibular incisor: ii/OLP & +71.03 & +69.12 to +72.93 & +76.45 & +74.22 to +78.68 \\
\hline Maxillary molar: ms/Olp & +49.42 & +47.76 to +51.08 & +50.34 & +48.47 to +52.22 \\
\hline Mandibular molar: mi/Olp & +47.31 & +45.37 to +49.25 & +52.28 & +50.35 to +54.21 \\
\hline
\end{tabular}

Table III. Change in Pancherz analysis variables

\begin{tabular}{|c|c|c|}
\hline & \multicolumn{2}{|c|}{ Twin-block } \\
\hline & Mean & $95 \% C I$ \\
\hline Overjet: Is/OLp minus ii/OLp & -6.65 & -7.98 to -5.32 \\
\hline Molar relation: Ms/OLp minus mi/Ollp & -4.04 & -4.84 to -3.24 \\
\hline \multicolumn{3}{|l|}{ Skeletal changes } \\
\hline Maxillary base: A point to Olp & -0.26 & -0.91 to -0.33 \\
\hline Mandibular base: $\mathrm{Pg} / \mathrm{Olp}$ & +3.95 & 3.19 to 5.75 \\
\hline Condylar head: $\mathrm{Co} / \mathrm{Olp}$ & -0.75 & -1.54 to 0.04 \\
\hline Mandibular length: pg/Olp plus co/OLP & +3.20 & 1.66 to 4.74 \\
\hline \multicolumn{3}{|l|}{ Dental changes } \\
\hline Maxillary incisor: is/Olp - ssOLp & -1.48 & -2.41 to -0.56 \\
\hline Mandibular incisor: ii/OLP Pg/OLp & +1.47 & 0.72 to 2.22 \\
\hline Maxillary molar: ms/Olp - ss/OlP & -0.67 & -0.11 to 1.44 \\
\hline Mandibular molar: mi/Olp - Pg/OLp & +1.02 & 0.39 to 1.64 \\
\hline
\end{tabular}

for A/OLp to $0.72 \mathrm{~mm}$ for Pg/OLp. These were acceptable error levels.

\section{DISCUSSION}

The results of this study show that the clip-on fixed functional appliance is an effective and rapid method of treating Class II malocclusion; it appears to be well accepted by patients. It is difficult to make comparisons between our data and other studies because of the dearth of prospective investigations. However, if these data are compared with those from an randomized controlled trial of the effectiveness of Herbst and Twin-block appliances, it appears that the treatment times obtained with this appliance are slightly less. ${ }^{3}$ When we compare the cephalometric measures, it also appears that this appliance produces somewhat similar changes to both the removable Twin-block and the Herbst appliance; these, of course, included normal mandibular growth. The only factor that influenced the final discrepancy was the pretreatment discrepancy. It appears that treatment contributes to reducing the discrepancy but does not totally eliminate it. Finally, the results of treatment as recorded by the PAR index show that this treatment is highly effective.

Our most important clinically relevant finding was the treatment completion rate. This was substantially more than our previous study in which we had noncompletion rates of $13 \%$ and $33 \%$ for the Herbst and the Twin-block appliances, respectively. ${ }^{3}$ It therefore appears that this appliance is well tolerated, and its use seems to obtain high levels of cooperation. It is impossible to compare our completion rates with noncompliance rates for other appliances because similar data has not been published.

Importantly, the mean number of visits needed to repair the Herbst appliances in our previous study was 4.3 ; in this study, the mean number of additional visits was 2.3. Therefore, we can assume that the clip-on fixed functional appliance fractures less than the version of the Herbst appliance that we evaluated. There could be several reasons for this. First, in the Herbst appliance, the pistons connect the maxillary and man- 


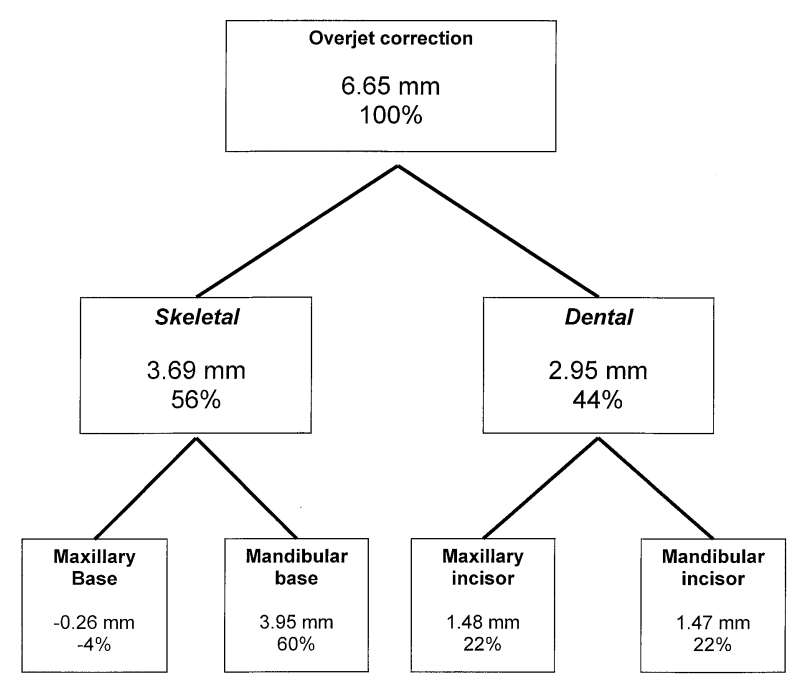

Fig 6. Contribution of skeletal and dental change to overjet correction.

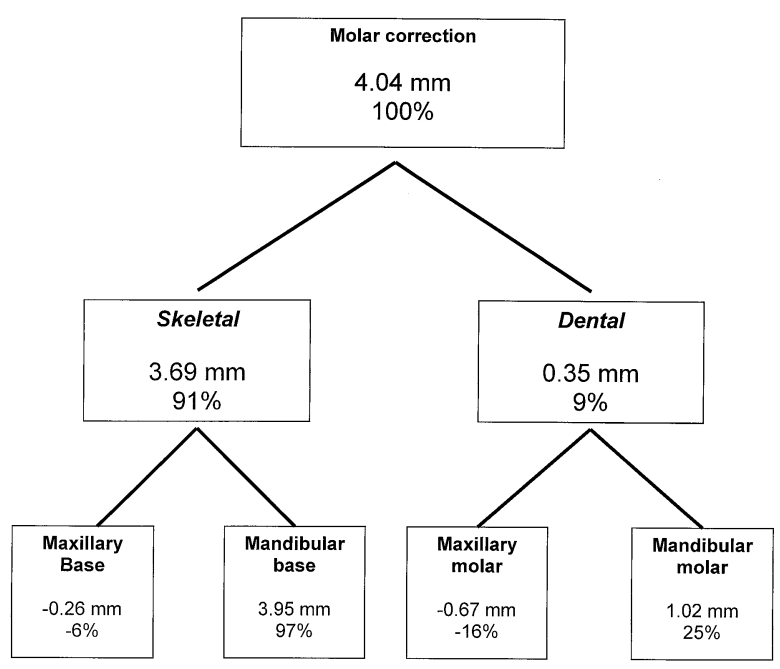

Fig 7. Contribution of skeletal and dental change to molar correction.

dibular appliance, and this might lead to stresses on the appliance components, particularly in lateral excursions. Furthermore, orthodontic bands and standard wire components retain the appliance, and this might lead to increased flexibility of the appliance and more resistance to flexural forces. In addition, the acrylic blocks might distribute the vertical forces of occlusion to the occlusal surfaces of the teeth and minimize the possibility of breakage.
It appears that, when the appliance breaks, the repair is fairly straightforward; this frequently involved replacing loose blocks or bands. If a band had split, it was replaced. When a Herbst appliance fractures or becomes detached, the chairside time needed for repair can be excessive.

This was a prospective cohort study, without a control. This study design was adopted to evaluate the feasibility of the appliance. As a result, this might be considered the first stage in developing this method of treatment. We should not assume that this appliance is better than other fixed or removable functional appliances. To answer this question, we must carry out a randomized clinical trial; this is the next stage of our investigation into this type of treatment.

\section{CONCLUSIONS}

This prospective cohort study showed that (1) this modification of the Twin-block appliance is an effective method of treating Class II malocclusion in terms of the morphological effects on the dental and skeletal tissues; and (2) the main theoretical advantages of this appliance over the removable Twin-block are that patient cooperation is enhanced and the appliance is active for 24 hours a day, there is no transition phase between the functional and fixed appliance phases, and it is less bulky.

\section{REFERENCES}

1. Pancherz H. The mechanism of Class II correction in Herbst appliance treatment. Am J Orthod 1982;82:104-13.

2. Franchi L, Baccetti T, McNamara JA. Treatment and posttreatment effects of acrylic splint Herbst appliance therapy. Am J Orthod Dentofacial Orthop 1999;115:429-38.

3. O'Brien K, Wright J, Conboy F, Sanjie Y, Mandall N, Chadwick $\mathrm{S}$, et al. Effectiveness of treatment for Class II malocclusion with the Herbst or Twin-block appliances: a randomized, controlled trial. Am J Orthod Dentofacial Orthop 2003;124:128-37.

4. Clark WJ. Twin-block functional therapy. London: Mosby-Wolfe; 1995.

5. Chadwick S, Banks P. The use of myofunctional appliances in the UK: a survey of British orthodontists. Dental Update 1998;25: 302-8.

6. Read MJF. The integration of functional and fixed appliance treatment. J Orthod 2001;28:13-8.

7. Richmond S, Shaw WC, O'Brien KD, Buchanan R, Jones R, Stephens CD, et al. The development of the PAR index (Peer Assessment Rating): reliability and validity. Eur J Orthod 1992; 14:125-39.

8. Hassel B, Farman AG. Skeletal maturation evaluation using cervical vertebrae. Am J Orthod Dentofacial Orthop 1995;107:5866. 